\title{
Administración y arbitraje: resolver de otra manera los conflictos (Crónica del curso de verano organizado por la UIMP los días 6, 7 y 8 de julio de 1994)
}

\author{
Carolina Sàenz Casals \\ Departamento de Derecho Administrativo \\ y Procesal de la Universidad de Barcelona
}

En el marco del Palacio de Pedralbes, dentro de los Cursos de Verano que organiza la UIMP en colaboración con la Escuela de Administración Pública de la Generalitat de Catalunya tuvieron lugar durante los días 6, 7 y 8 de julio de 1994 las Jornadas sobre Administración y arbitraje: resolver de otra manera los conflictos (terminación convencional, recurso administrativo, conciliación, mediación, transacción y arbitraje en materia administrativa).

El actual contexto de sobrecarga de la Administración de Justicia, agravado por la tendencia creciente de la litigación, ha puesto de relieve que la resolución judicial de los conflictos no es suficiente y ha dado lugar a una búsqueda generalizada de vías para, por un lado, prevenir el contencioso y, por otro, resolver los conflictos de forma ágil y flexible, mediante procedimientos no formalizados y sumarios. Estas nuevas propuestas de resolución de litigios han sido el objeto principal de las Jornadas, puesto que la mención expresa de su posible aplicación en materia administrativa en el artículo 107.2 de la Ley 30/92, de 26 de noviembre, del Régimen Jurídico de las Administraciones Públicas y del Procedimiento Administrativo Común (en adelante, LRJPAC) obliga a plantear su estudio.

El curso se estructuró a través de tres ponencias diarias, seguidas cada una de un debate que, dada la condensada sucesión de las intervenciones, en ocasiones tuvo que ser más breve de lo deseado. La mayoría de los conferenciantes optó no por tratar de diseñar el régimen jurídico concreto de estos nuevos procedimientos de lege ferenda, sino por estudiar cuáles son las posibilidades reales de aplicación en materia administrativa de estas figuras que tienen su origen en el Derecho privado. Elegir este enfoque fue, en mi opinión, más enriquecedor, porque permitió contrastar los puntos de vista - no siempre coincidentes- de los intervinientes sobre la viabilidad real de estas propuestas. 
El objeto de esta crónica no es el de resumir los contenidos y conclusiones del Curso, sino el de transmitir qué dirección sigue la llamada búsqueda de formas alternativas a la resolución judicial de los conflictos entre la Administración y los ciudadanos y cuáles son las impresiones sobre su oportunidad, conveniencia y operatividad real.

La primera ponencia del Curso estuvo a cargo de Danièle LochaK, Catedrática de Derecho administrativo de la Universidad de París, X, Nanterre y llevó por título "Problemas actuales de la justicia administrativa en Francia. El recurso administrativo como alternativa».

Considero muy acertado, por parte de los organizadores, que la primera intervención tratase sobre cómo se plantea la cuestión de los modos alternativos de resolución en el sistema de justicia administrativo francés, teniendo en cuenta que los instrumentos y categorías de nuestro Derecho administrativo tienen sus raíces en Francia y siguen una evolución paralela. La ponente partió de la actual explosión del contencioso-administrativo francés que trató de paliarse mediante la Ley de 1987 de Reforma de la Jurisdicción Administrativa y que dio origen al Rapport del Conseil d'État francés "Régler autrement les conflits: conciliation, transaction, arbitrage en matière administrative», dictamen que fue punto de referencia obligado en ésta y en muchas de las sucesivas ponencias.

El núcleo de su exposición se centró en plantear el recurso administrativo como un modo alternativo a la resolución judicial de los conflictos, porque puede evitar que el asunto llegue al juez, a pesar de que, ya de entrada, señaló que por razón de cultura de funcionamiento, a la Administración le cuesta mucho cambiar el sentido de su decisión. Hizo constar la necesidad de distinguir entre el carácter obligatorio o facultativo del recurso según las materias y reseñó los presupuestos que, según el Rapport del Conseil d'État citado, tendrían que cumplirse para que el recurso administrativo fuese verdaderamente efectivo: asegurar que la Administración examinase efectivamente los recursos que se plantean, que los resolviera algún órgano separado de la línea jerárquica y configurarlos con carácter suspensivo del acto impugnado.

En cuanto a la búsqueda de otros modos alternativos, se refirió sucintamente a la conciliación y a la figura del Médiateur, pero en todo momento dejó claro que, en su opinión, la solución al colapso actual pasaba por la mejora del vigente sistema de justicia administrativa y por la recuperación del recurso administrativo, y no tanto por la búsqueda de otros medios quizá más imaginativos pero de futuro más incierto. 
ADMINISTRACIÓN Y ARBITRAE: RESOLVER DE OTRA MANERA LOS CONFLICTOS

La exposición del Catedrático de Derecho administrativo de la Universidad de Barcelona Joaquim ToRNos sobre «El recurso administrativo previo: posibilidades y perspectivas", partió, también, de la situación de crisis de la justicia administrativa, que había tratado de paliarse mediante reformas organizativas, la búsqueda de medios alternativos ADR y la recuperación del procedimiento administrativo como medio para evitar el proceso contencioso.

En este último sentido y partiendo de la constitucionalidad de establecer vías previas reiteradamente declarada por el TC (por todas, ver la STC de 29 de noviembre de 1993), defendió la necesidad de revalorizar la figura del recurso administrativo, tradicionalmente criticado por la doctrina española por el hecho de haber sido concebido como un mecanismo de control interno que jugaba como un privilegio de la Administración y como un mecanismo dilatorio del acceso al juez.

El ponente hizo constar las modificaciones principales introducidas por la LRJPAC en esta materia (básicamente, la eliminación del recurso de reposición y el mantenimiento del recurso de alzada con el nombre de recurso ordinario) y detectó los problemas más importantes que ya se apuntan, especialmente en el ámbito de la Administración local donde el recurso de reposición era, de hecho, el único operativo.

El Dr. ToRnos partió de la posibilidad que ofrece el artículo 107.2 de la LRJPAC de "sustituir el recurso ordinario por otros procedimientos de impugnación o reclamación incluidos los de conciliación, mediación y arbitraje» para hacer una propuesta de recuperación del recurso administrativo concebido desde nuevos postulados, no como un mecanismo de control interno de la Administración sino como una garantía del administrado. Concretó los presupuestos que la nueva regulación debería cumplir en los siguientes: introducirlo sectorialmente, distinguiendo entre su carácter obligatorio o facultativo según la litigiosidad de la materia; fomentar la especialización de los componentes de los órganos que, por otro lado, deberían estar separados de la línea jerárquica; discutir sobre la conveniencia de que estos órganos tuvieran facultades de resolución o sólo de propuesta y, en último lugar, destacó el carácter no formal que debería tener el procedimiento en vía de recurso.

Como conclusión reseñó las ventajas de este nuevo modelo de recurso administrativo que permitiría abrir una cierta negociación entre la Administración y el ciudadano, teniendo más en cuenta las cuestiones de oportunidad. Me pareció interesante la idea que el ponente dejó apuntada de que estos órganos pudieran cumplir una fun- 
ción complementaria: la de abrir una línea de comunicación activa mediante memorias anuales, informando a la Administración de qué materias presentan más litigiosidad, corrigiendo su actuación y prestando un cierto asesoramiento.

Estas dos ponencias definieron un primer bloque que se centró en la revalorización del recurso administrativo como mecanismo para aliviar el proceso contencioso, mediante propuestas sugerentes, fruto de una madurada reflexión, con la voluntad de mejorar y aprovechar el actual sistema de justicia administrativa.

A continuación expondré un segundo grupo de ponencias que tuvieron por objeto la posible aplicación en materia administrativa de procedimientos o figuras que tienen su origen en el Derecho privado y que constituyen la cara nueva de la búsqueda de medios alternativos.

Miguel SÁNCHEz MORÓN, Catedrático de Derecho administrativo de la Universidad de Alcalá de Henares, inició este segundo bloque con una exposición que llevaba por título "La mediación en materia administrativa: ámbito e instrumentos organizativos para hacerla efectiva».

Tomó como punto de partida las actuales propuestas respecto a la solución de los conflictos que van desde la desjudicialización del sistema (dado que la resolución judicial de los conflictos ya no parece la más idónea), hasta la desestatalización del sistema (buscar los medios de solución en la iniciativa privada y en las instituciones sociales), pasando por la desjuridificación (intervención de otro tipo de expertos no juristas, dada la excesiva complejidad del contenido de las resoluciones judiciales y su alejamiento de la idea de justicia material).

Definió como esencia de la mediación el hecho de que el tercero neutral organiza el intercambio de los puntos de vista y trata de aproximar sus intereses sin imponer una decisión. Y ahí residen precisamente la virtud y el inconveniente de la mediación: la virtud, porque las partes son las responsables de buscar no tanto la racionalidad jurídica como el equilibrio de sus intereses; el inconveniente, porque, como el mediador no puede imponer su decisión, no está asegurada la resolución del conflicto.

Señaló que, tradicionalmente, la mediación había jugado un papel importante en el Derecho privado y en el Derecho internacional. Respecto a la mediación en materia administrativa en España, se refirió a 
ADMINISTRACION Y ARBITRAJE: RESOLVER DE OTRA MANERA LOS CONFLICTOS

la escasa regulación existente sobre este tema antes de la LRJPAC (algunas leyes de los comisionados parlamentarios -como la del Síndic de Greuges de Catalunya- prevén que éstos tengan ciertas funciones de mediación; el artículo 30 de la Ley 9/1987, de órganos de representación, determinación de las condiciones de trabajo y participación del personal al servicio de las Administraciones públicas abre la posibilidad de nombrar un mediador entre las Administraciones públicas y los sindicatos).

Respecto a la previsión del artículo 107.2 de la LRJPAC de la mediación como uno de los procedimientos susceptibles de sustituir sectorialmente al recurso ordinario, el ponente hizo las siguientes observaciones: podría resolverse mediante este procedimiento cualquier controversia susceptible de ser resuelta mediante compromiso o acuerdo, por lo cual, los campos idóneos serían el de las potestades discrecionales y aquél en el que la Administración actuara sometida al Derecho privado.

Respecto a los instrumentos organizativos de la mediación, destacó el ponente que la mediación, en sí, no requería ninguno, pero que para estimular su uso por los particulares sería conveniente publicar listas de mediadores y tomar otras medidas que facilitaran el acceso a ella.

Pese a que comenzó su intervención afirmando que «no hay que sacralizar la Administración de justicia sino la función que desempeña», el ponente se mostró más bien pesimista respecto a las posibilidades abiertas por el 107.2, en primer lugar, por el hecho de que dicha previsión es una especie de " $2 .^{\text {a }}$ instancia", ya que la mediación entra en juego una vez ya se ha producido una decisión de la Administración y, en segundo lugar, porque la mediación requiere un tiempo indeterminado que posiblemente no sería compatible con la limitada duración que por fuerza ha de tener el procedimiento administrativo. En esta línea, apuntó que la mediación podría tener más juego a través del artículo 88 de la LRJPAC, es decir, como medio de finalización del procedimiento.

Concluyó afirmando que, a su entender, aún debería transcurrir bastante tiempo antes de que la resolución judicial dejara de ser la forma principal de resolver los conflictos entre la Administración y los ciudadanos.

La conferencia del Catedrático de Derecho administrativo de la Universidad Complutense de Madrid, Tomás Ramón FERNÁNDEZ versó, 
precisamente, sobre «La terminación convencional: naturaleza, ámbito $y$ limites".

El ponente se mostró desde el comienzo escéptico respecto de las posibilidades pro futuro del artículo 88 de la LRJPAC de terminar los procedimientos administrativos según fórmulas convencionales y no conflictuales. Puso de relieve que este artículo no instrumenta ninguna forma de resolución convencional sino que se remite a futuras regulaciones; por otro lado, tampoco establece el ámbito ni los límites de aplicación de esta forma de terminación, sino que sólo dispone, de modo muy genérico, que «los acuerdos, pactos, convenios o contratos entre la Administración y los administrados a los que se llegue no podrán ser contrarios al ordenamiento jurídico ni recaer sobre materias no susceptibles de transacción y que deberán satisfacer el interés público».

Entendió el ponente que estas fórmulas convencionales, independientemente de su concreción, chocarían siempre con dos límites: el principio de legalidad (las potestades regladas) y el principio de igualdad (que podría vulnerarse si se llegara a distintos acuerdos en situaciones jurídicas equiparables), límites que tendrían que acotar el diseño de las fórmulas transaccionales, pero no eliminar la posibilidad de su existencia.

Según el ponente, dicho precepto no es tan novedoso como a primera vista parece, sino que no es más que un reconocimiento genérico de regulaciones específicas ya existentes (como los convenios expropiatorios de la LEF o la resolución del contrato por mutuo disenso) y a las cuales la jurisprudencia había dado carta de naturaleza. Por eso, como conclusión final, a pesar de que valoró positivamente que se hubiera recogido de modo expreso en una ley la posibilidad genérica de la terminación convencional, porque ello manifiesta una evolución y un cambio de perspectiva en cuanto a la posición y actuación de la Administración, afirmó que el artículo 88 reflejaba una regulación apresurada que, de hecho, no introducía innovaciones, por lo cual no podía hablarse de una revolución jurídica.

Como réplica a una observación de uno de los asistentes sobre la conveniencia de tomar la Ley alemana de 1976 y la doctrina italiana sobre los accordi procedimentali como referente para instrumentar en nuestro ordenamiento jurídico las fórmulas convencionales de resolución de conflictos, Tomás Ramón FERNÁNDEZ señaló, entiendo que acertadamente, que la cuestión ahora estaba no tanto en fijarse en la técnica jurídica concreta, sino que previamente hacía falta superar un problema de 
ADMINISTRACIÓN Y ARBITRAJE: RESOLVER DE OTRA MANERA LOS CONFLICTOS

mentalidad, ya que resolver mediante convenio o acuerdo no dejaba de ser una cesión de poder por parte de la Administración. Primero, hace falta introducir esta nueva cultura y, luego, ya vendrá la técnica jurídica.

La siguiente conferencia sobre "El arbitraje en materia administrativa» corrió a cargo del Catedrático de la Universidad Complutense de Madrid, Alejandro NiETo. A mi entender fue una de las intervenciones más brillantes, no sólo por su contenido sino sobre todo por la forma, ya que el Catedrático demostró una vez más su excelente dominio de la lengua y su habilidad para mantener vivo el interés a lo largo de toda la intervención que, a pesar de que el ponente respetó escrupulosamente el tiempo que le había sido asignado, resultó para la mayoría de los asistentes, breve.

Inició su ponencia afirmando que el arbitraje que se prevé en el artículo 107.2 de la LRJPAC se aparta del arbitraje clásico porque no cumple las tres premisas que lo caracterizan: la de ser una sustitución de la figura judicial, la de ser voluntariamente aceptado por las partes $y$, finalmente el hecho de que sean las partes las que designen a los árbitros.

Alejandro NIETo entendió que estos requisitos no se observan en la figura del 107.2, porque en este precepto el arbitraje no sustituye el control judicial, sino que sólo sustituye al órgano de resolución del recurso administrativo. Por otro lado, el legislador prescinde de la voluntariedad del arbitraje y permite que las leyes sectoriales posteriores lo establezcan con carácter forzoso y, en tercer lugar, la designación de los árbitros no está a la disposición de las partes. A pesar de estas observaciones y del hecho de que el legislador de la LRJPAC no regula el arbitraje sino que se remite a leyes posteriores, entendió el ponente que había que felicitarse de la sensibilidad del legislador que había detectado esta necesidad de encontrar modos alternativos a la resolución judicial de los conflictos en materia administrativa. Por ello, trató de avanzar un diseño del posible régimen jurídico del arbitraje en Derecho administrativo de lege ferenda.

De entrada, señaló que el artículo 107.2 diseñaba un marco que el legislador autonómico debería respetar, dado su carácter de ley básica, pero que el legislador estatal podía obviar mediante leyes posteriores. En consecuencia, y en relación al ámbito de aplicación del arbitraje, que se prevé como sustitutivo del recurso ordinario, el ponente propuso que de lege ferenda sería adecuado posibilitar el juego del arbitraje para sustituir a las reclamaciones previas al ejercicio de acciones civiles y laborales, lo cual no es posible con la regulación actual en la mano porque 
en estos casos no estamos delante de un recurso ordinario. En cuanto a la alternativa entre el arbitraje de derecho y el de equidad, entendió que no era absurdo pensar en el arbitraje de equidad cuando una de las partes fuese una Administración pública, porque, a veces, dentro de la legalidad caben infinidad de soluciones todas ellas legales. Respecto a la ejecución del laudo, señaló que podría pensarse que lo ejecutaran no los Tribunales sino la propia Administración, a través de los medios de ejecución de los actos administrativos, lo cual implicaba cuestionarse previamente si el laudo arbitral era en estos casos un acto administrativo. Finalmente defendió la necesidad de establecer mecanismos de suspensión y de distinguir sectorialmente los ámbitos en los que sería oportuno el arbitraje como forma de resolución.

Acabó concluyendo que la referencia del 107.2 a los «ámbitos sectoriales determinados" y a la "especificidad de la materia» eran, en realidad, tan generales que lo permitían casi todo, de modo que el resultado final dependería de si se hacía o no el cambio de mentalidad a que se refería Tomás Ramón FERNÁNDEZ, cambio de mentalidad no sólo de la Administración, sino también del legislador, de los tribunales y de los ciudadanos.

La ponencia del Catedrático de Derecho administrativo de la Universidad de Málaga, Ángel SáNCHEZ BLANCO, titulada "La transacción en materia administrativa: régimen jurídico" fue, seguramente, la que más detalló y concretó el posible régimen jurídico de esta figura en el Derecho administrativo.

Comenzó la exposición recordando cuál era la regulación de la transacción en el CC (artículos 1809 y ss.), destacando que en el Derecho privado la transacción se basaba en la existencia de una relación conmutativa y en la paridad de las partes, presupuestos que en las relaciones de Derecho público se matizaban. La jurisprudencia civil ha destacado como características de la transacción civil la necesidad de una relación jurídica incierta y la exigencia de recíprocas concesiones, por lo cual, podría calificarse como un contrato liquidativo (entre otras, STS de 4 de abril y de 16 de mayo de 1991).

El ponente puso de manifiesto que el CC había tenido una visión prospectiva, ya que el artículo 1812 ya preveía la posibilidad de que las corporaciones con personalidad jurídica pudiesen transigir.

El núcleo de su conferencia fue la disección de los requisitos que debería cumplir la transacción en materia administrativa a partir de un 
estudio minucioso y detallado de los dictámenes del Consejo de Estado; como más destacables, hizo constar que sólo la posesión de derechos (no de intereses) legitimaba para la transacción, que ésta tenía que estar orientada por el interés público, que tenía que ofrecer respuesta a una previa situación dudosa o incierta y que no requería exigencias formales específicas.

Criticó la interpretación que aplicaba a la transacción sobre los derechos de la hacienda pública de las Comunidades Autónomas el artículo 39 LGP (TR por D-Leg. 1091/88), que exige RD acordado en Consejo de Ministros, previa audiencia del Consejo de Estado en pleno. A su entender, esta interpretación no casaba con el concepto mismo de autonomía; sobre todo teniendo en cuenta que las leyes del Consell Consultiu de la Generalitat de Catalunya y de la Comissió Jurídica Assesora habían prescindido del dictamen del órgano consultivo.

Como conclusión, hizo constar que, precisamente, la ventaja de la transacción era la de permitir una gran libertad a las partes, que no encontraban más límites que los ligados a la posibilidad misma de transigir y a la ductilidad y flexibilidad del pacto transaccional.

La conferencia de Luis ORTEGA, Catedrático de Derecho administrativo de la Universidad de Castilla-La Mancha sobre "La conciliación en materia administrativa: significado y perspectivas» cerró este segundo bloque de ponencias que tenían por objeto el estudio de la aplicación en materia administrativa de figuras de origen privado para resolver los conflictos entre la Administración y los ciudadanos. A mi entender fue, junto con la de Alejandro NiETo, la exposición más interesante, ya que recogió los puntos de vista de los ponentes anteriores sobre la viabilidad de estas figuras, definió el suyo y, finalmente, trató el tema de la conciliación partiendo de la posición previamente adoptada.

Para este ponente, lo que justificaba la proliferación de estos medios alternativos no era la crisis de la justicia administrativa (punto de partida de numerosas intervenciones anteriores) sino el replanteamiento de la posición y del modus operandi de la Administración. Estos nuevos procedimientos no respondían a la voluntad de crear sucedáneos de justicia administrativa sino a la de pasar de una Administración imperativa a una Administración consensual, donde las partes no planteasen la imposición de su razón jurídica sobre la del otro, sino que buscasen el acuerdo. Por lo tanto, duda y diálogo frente a certitud e imposición. En este sentido, se alineó en el mismo punto de partida que Tomás Ramón FERNÁNDEZ y Alejandro NiETo. Teniendo en cuenta que la Constitución 
española no establece cómo han de definirse los intereses generales que la Administración ha de velar, entendió que dicho interés podía ser definido no sólo mediante el principio de legalidad (la vinculación positiva de la Administración a la ley), sino también a través del acuerdo y la composición. Las figuras del 107.2 debían de contemplarse dentro de esta nueva perspectiva de definición del interés general.

Luis OrTEgA, al contrario que Alejandro NiETo, defendió que el 107.2 definía un marco que vinculaba también al legislador estatal, precisamente por su carácter básico y que las figuras a las que se refería no podían establecerse con carácter forzoso.

Respecto a la conciliación, el ponente destacó como características definitorias que la misión del conciliador es sólo reunir a las partes; que en la conciliación, a diferencia de la transacción, una parte puede acogerse totalmente a la posición de la otra y que en esta figura se tiene mucho más en cuenta que en el arbitraje o en la mediación la oportunidad o conveniencia. A su entender, más que como un "procedimiento de impugnación o reclamación", la conciliación ha de concebirse como una comunicación o como un deseo de negociación, o sea, más bien como todo lo contrario de impugnar o reclamar. Entendió que sería aconsejable distinguir la composición del órgano conciliador según la materia (más o menos especialización) y que la independencia perdía importancia en esta figura porque, de hecho, eran las partes las que se conciliaban. Me pareció interesante la idea de crear un órgano interno de la Administración que dictaminase sobre la conveniencia de que la Administración se conciliara en cada caso concreto, dando carácter voluntario a sus dictámenes si fuesen contrarios a la conciliación. Finalmente, defendió la tasación de los motivos de impugnación del acuerdo, por causas vinculadas a la nulidad de los contratos y no por la vulneración de cualquier causa del ordenamiento jurídico, como si se tratase de un acto administrativo.

Pese a que esbozó estos apuntes en relación al régimen jurídico de la conciliación en materia administrativa, el ponente acabó su exposición poniendo de manifiesto que la función de la conciliación -reunir a las partes-, de hecho, ya la cumplía el recurso administrativo previo que, además, también permitía tener en cuenta criterios de oportunidad y de conveniencia.

Dado que en el recurso ordinario estaban presentes muchos de los elementos que se pedían a la conciliación, defendió que para él la solución venía por no inventar nuevos órganos que se conciliasen sino que lo que 
hacía falta era reclamar la neutralidad de la Administración, que es una exigencia constitucional, y recuperar el recurso administrativo.

Las dos últimas conferencias definieron y cerraron un último bloque temático, que tuvo por objeto la resolución extrajudicial en el Derecho anglosajón, que utiliza unos instrumentos y responde a unas coordenadas que se alejan de nuestra lógica jurídica, heredada del Derecho francés.

La primera ponencia, bajo el título de «La resolución de los conflictos en el Derecho inglés» la pronunció Spyridon FlogarTIS, Catedrático de Derecho administrativo de la Universidad Nacional de Atenas. Este ponente reunía la doble cualidad de ser un gran conocedor del Derecho inglés y, por otro lado, estar familiarizado con los instrumentos y conceptos de nuestro Derecho administrativo, lo cual hizo posible una introducción al tema de la resolución extrajudicial de los conflictos en el Derecho inglés clara, comparativa y enriquecedora.

Expuso tres vías para resolver extrajudicialmente los conflictos: de entrada, se refirió al Parlamentary Commissioner for the Administration, que, mediante un procedimiento gratuito y totalmente informal, recibe las quejas de los ciudadanos sobre la actuación de la Administración, a través de sus representantes parlamentarios. Por tradición cultural, el ciudadano británico que quiere demandar a la Administración es más propenso a acudir al Commissioner que a la jurisdicción y el sistema funciona porque, aunque los dictámenes no tienen fuerza coercitiva para obligar a la Administración, sí tienen una gran fuerza moral basada en la persuasión.

Como segunda vía, el ponente explicó que el Gobierno Major había creado una nueva institución, la Citizens Charter, que incita a la Administración a preparar un plan de trabajo para los años próximos y que recoge las quejas de los ciudadanos sobre el funcionamiento y la aplicación de dicho plan. La Citizens Charter tampoco tiene fuerza coercitiva, pero a través de su memoria anual puede tener una influencia importante. Señaló que los resultados estaban aún por ver.

Finalmente, expuso el sistema de los Administrative Tribunals, que fueron creados porque se sintió la necesidad de establecer algún mecanismo que permitiera el reexamen de los actos de la Administración, sin acudir a la justicia ordinaria; sin embargo, hizo notar que se observaba un progresivo acercamiento hacia ésta, ya que, en la actualidad, las decisiones de los Administrative Tribunals, no eran sentencias sino actos y que, por lo tanto, puede pedirse su anulación ante los tribunales ordinarios. 
En cuanto a la evolución futura de los Administrative Tribunals, el ponente avanzó que, según él, se introduciría en Gran Bretaña lo que ya se había creado en Australia: un Administrative Tribunal, de competencia general de $1^{\mathrm{a}}$ y de $2^{\mathrm{a}}$ instancia, con una composición eminentemente jurídica y un procedimiento más inquisitorial y menos contradictorio. De modo que el sistema de los Administrative Tribunals, de hecho, estaría a medio camino entre la alternativa y la subordinación respecto a la resoluación judicial de los conflictos.

La conferencia del Catedrático de Derecho administrativo de la Universidad pública de Navarra, Ignacio BORRAJO INIESTA, sobre "La resolución extrajudicial de los conflictos en el Derecho Norteamericano" clausuró este curso.

El ponente comenzó enmarcando el fenómeno de la proliferación de los Alternative Dispute Resolution (ADR) en EE. UU. en su contexto, como una respuesta a una voluntad de desjuridificar el sistema que, de hecho, tenía como paladines a los sociólogos, psicólogos y asistentes sociales. Explicó que en EE. UU. este movimiento tenía un alcance muy amplio, ya que se aplicaba no sólo a la resolución de conflictos sino también como alternativa al procedimiento clásico de elaboración de normas y de formulación de políticas públicas. Los ADR incluyen técnicas muy variadas (arbitraje, mediación, minijuicios, la negociación, el fact finding...) y todas se basan en el principio de construir una relación de confianza entre las partes, en la sinceridad en el manejo de los datos de hecho y, en definitiva, en la voluntad de romper el esquema del adversario y de ir hacia un sistema de colaboradores.

La Alternative Dispute Resolution Act de 1990, más que de establecer reglas legales se preocupa de que existan los medios legales y materiales para que se lleven a cabo los ADR y encarga a la Administrative Conference que los potencie mediante cursos de formación, subvenciones, etc... Los ADR tienen carácter voluntario; las personas encargadas de ejercitarlos se reconducen a la figura del neutral y pueden ser funcionarios o particulares; se difiere al desarrollo reglamentario la definición del perfil profesional que han de reunir; se regula con gran detalle el principio de confidencialidad, que es uno de los pilares de los ADR y se plantea el problema de cómo conciliarlo con el principio de transparencia que rige en el Derecho norteamericano. La ADR Act da un protagonismo importante a la regulación del arbitraje, porque es la figura que ha planteado más problemas de constitucionalidad, ya que las partes se someten a la decisión del árbitro. 
ADMINISTRACION Y ARBITRAJE: RESOLVER DE OTRA MANERA LOS CONFLICTOS

Como conclusión, el ponente advirtió que era preciso ser cauteloso en el traslado de los ADR a nuestro ordenamiento jurídico, porque el contexto en que éstos se insertaban era muy diferente del español en el que la lógica del acuerdo y de la negociación es extraña.

Estas y otras cuestiones fueron las expuestas y sugeridas a lo largo de las tres jornadas por ilustres representantes de la doctrina administrativista española y extranjera.

La idea de fondo que claramente se desprendió de todas las ponencias fue el hecho de que la proliferación de estos medios alternativos a la resolución judicial de conflictos en materia administrativa no se ha producido de forma casual, sino que tiene un importante trasfondo ideológico: no se trata simplemente de arbitrar técnicas para resolver la situación de colapso de la justicia contencioso-administrativa, sino que responde a un cambio en la concepción de la actuación de la Administración, a la voluntad de alejarse progresivamente de la idea de imperio e imposición y de avanzar hacia la negociación y el acuerdo consensuado para poner fin a sus conflictos con los particulares.

Suscribo plenamente la afirmación de que es preciso que cuaje previamente este nuevo enfoque para que los medios alternativos que se proponen -que, en tanto que adaptaciones de figuras de origen privado, parten de presupuestos distintos- puedan ser realmente eficaces en materia administrativa.

Entretanto, creo que es importante mejorar el actual sistema de justicia administrativa, recuperando y aprovechando al máximo los instrumentos que ya existen - por todos, el recurso administrativo- con el objetivo de reducir el número de recursos ante el juez contencioso. De hecho, a pesar de que actualmente el tiempo en el proceso contencioso juegue a favor de la Administración, a ésta le interesa también reducir el contencioso, porque, al fin y al cabo, disminuir el contencioso no deja de ser promover la imagen de una Administración moderna. 
REALA-1994, núm. 264. SAENZ CASALS, CAROLINA. ADMINISTRACION Y ARBITRAJE: RESOLV... 